\title{
Fit for purpose? The appropriate education of health professionals in South Africa
}

Sixty years ago Sidney and Emily Kark had a vision to make health care accessible to all South Africans, particularly those in rural and under-served areas. ${ }^{1}$ They established a comprehensive primary health care model that was replicated in over 40 rural communities before the apartheid government abolished their plan. In the light of these historic initiatives, what have health sciences training institutions achieved in the past 50 years to address the health care priorities of South Africans who are most in need?

In 2008 there were approximately 250000 health care professionals employed in South Africa, with a calculated shortage of about 80000 in the public sector and vacancy rates for doctors in excess of $50 \%$ in several provinces. ${ }^{2}$ There is a serious overall shortage of health care personnel and the maldistribution of the health workforce between the public sector and private sector is great. At least $70 \%$ of all doctors work in the private sector, leaving only approximately 10600 doctors to provide service for the $85 \%$ of South Africans who do not have private health insurance. ${ }^{3}$ While the public-private health care situation is far from equitable, the situation in the rural areas of South Africa is appalling. At least $46 \%$ of South Africa's 49 million rural residents are served by only $12 \%$ of our doctors, mostly from the public sector, and $19 \%$ of our nurses. ${ }^{4}$ Not only are the public health services grossly insufficient and inequitable, but some of our medical schools have the greatest proportion of emigrating health care professionals in the world. ${ }^{5}$ The facts speak for themselves - we need to train more health care professionals, improve the retention of health care personnel in South Africa, improve doctor-to-population ratios in public health care facilities, and distribute doctors better so as to address the health care needs of marginalised communities.

Several government initiatives have been implemented to address these health workforce needs. All new graduates complete a year of community service after internship, about half of which are in rural or under-served communities. Although this step has made some impact on the shortage of doctors in the public service, it is not an effective retention strategy. For continuity it is better to have one doctor in a post for 5 years than five doctors for 1 year each. Furthermore, it appears that obligatory service may have negative unintended consequences, and it could be seen as 'immunising' young graduates to further work in the public service. A study of community service doctors showed that $18 \%$ of them indicated an interest in working in a rural area after they had completed their obligatory time, ${ }^{6}$ whereas much fewer actually do. Furthermore, the government offers additional financial remuneration for health professionals working in rural areas. Although this may influence the short-term career choices of up to one-third of health professionals working in rural areas, financial remuneration is not the only factor influencing career choices. ${ }^{7}$ Equally important motivators are factors such as job satisfaction, career advancement, work conditions and educational opportunities.

While these measures go some way to addressing the publicprivate and urban-rural inequalities of health care, we need more health care professionals in total if we are to come close to addressing the country's needs. The National Human Resources Plan for Health, published in 2006, indicated that we need to double the number of South African medical graduates from 1200 to 2400 by $2014 .^{8}$ This cannot take place within the current framework for health sciences training, and serious consideration must be given to developing another health sciences training institution in South Africa. Since evidence indicates that medical schools situated in rural areas are more likely to produce graduates who work in rural areas, ${ }^{9-11}$ it seems appropriate that an additional training institution should be located in a province with a large rural population without a medical school, such as Mpumalanga.

What should medical schools do to address these needs? Firstly, local and international evidence indicates that students of rural origin are more likely to return to rural practice after graduation. ${ }^{11-14}$ It is therefore appropriate that applicants of rural origin be prioritised for admission to health sciences faculties in South Africa today. A recent review found that less than one-third of medical students trained in South Africa are of rural origin. ${ }^{15}$ Innovative programmes to recruit such students to urban medical schools are in place at some centres and other innovative ways of achieving this goal should be developed. ${ }^{13}$ In addition to admission criteria, it is essential that recruitment processes are suitably adjusted to cater for students from disadvantaged backgrounds.

Shortly after the election of a democratic government in South Africa, a new Health Act was promulgated, which emphasised the need for a primary health care based approach to the delivery of health care at all levels. These principles must therefore form the foundation of health sciences curricula and be made explicit to students at all stages of their undergraduate education. The primary health care discourse has found expression in numerous ways in individual curricula around the country. ${ }^{16}$ The paper on medical curricula in this issue of the journal ${ }^{17}$ suggests that it needs to be made more explicit all the way from the mission statement of the university to the bedside where students are taught.

Another evidence-based aspect of health sciences education that has been addressed to a variable extent is the introduction of medical students to rural clinical practice during their undergraduate years. While all faculties offer short placements of between 2 and 8 weeks, longitudinal placements extending up to a year are being implemented in some faculties. ${ }^{18}$ Serious consideration needs to be given to this strategy given the preliminary evidence emerging from Australia, USA and Canada regarding the outcomes of 'longitudinal' clinical clerkships. ${ }^{19}$ In addition to enhancing the integration of knowledge and skills, longitudinal placements of one year or more appear to increase the likelihood of choosing a rural career. ${ }^{20,21}$

Major challenges must be overcome to successfully deliver health sciences education at the level of community and district health care services in South Africa. These include physical teaching space in clinics not designed to accommodate students, heavy clinical workloads of health care workers seeing large numbers of patients each day, and academics willing to teach and work in primary care settings. We need to address these limitations to take students to the appropriate levels of health care service delivery in a sustainable manner which is also beneficial to the communities we serve.

It is well recognised that 'assessment drives learning', and the importance of primary health care needs to be emphasised by making it a fundamental component that is integrated into assessment processes in undergraduate education. Assessment practices clearly indicate to students what is valued by the faculty and so the implication is obvious: assess what is important, and students will adopt the values held in high regard by the faculty. A further concern about current assessment practices is that we aim to teach students in district-level facilities, but they return to tertiary teaching hospitals to be examined on learning experiences gained in district hospitals and community-based clinics. Such practices ultimately undermine the message about the importance and relevance of primary care. 
Finally, the question of programme evaluation must be addressed. There are limited data on the key outcomes of our academic endeavours, for example the type and location of clinical practice of our graduates. We need more programme evaluation and research to endorse the major curriculum changes we have undertaken and are undertaking. The ultimate and overarching question we need to answer as we enter the next decade is whether our graduates are 'fit for purpose' in the context of the gross inequities in the health sector in which we find ourselves.

\section{Vanessa Burch}

Department of Medicine

Faculty of Health Sciences

University of Cape Town

\section{Steve Reid}

Primary Health Care Directorate

Faculty of Health Sciences

University of Cape Town

Corresponding author: S Reid (steve.reid@uct.ac.za)

\section{References}

1. Gofin J. On 'A practice of social medicine' by Sidney and Emily Kark. Social Medicine 2006;1:107-115 2. Development Bank of South Africa. DBSA roadmap process. 2008. http://www.dbsa.org/Research/ Documents/Health\%20Roadmap.pdf (accessed 2 November 2009).

3. Health Economics and HIV \& AIDS Research Division (HEARD). Human Resources for Health: A Needs and Gaps Analysis of HRH in South Africa. Durban: HEARD, University of KwaZulu-Natal, 2009.
4. Hamilton K, Yau J. The global tug-of-war for health care workers. http://www.hrhresourcecenter.org/ node/1264 (accessed 2 December 2009)

5. Hagopian A, Thompson MJ, Fordyce M, Johnson KE, Hart LG. The migration of physicians from subSaharan Africa to the United States of America: measures of the African brain drain. Human Resources for Health 2004;2:17. http://www.human-resources-health/content/2/1/17 (accessed 17 December
for for Heas).

6. Reid SJ. Community service for health professionals. In: South African Health Review 2002. Durban: Health Systems Trust, 2003: chapter 8. http://www.hst.org.za/publications/527 (accessed 1 December 2010).

7. Reid S. Monitoring the effect of the new rural allowance for health professionals. Health Systems Trust, Durban, South Africa. 2004. http://www.hst.org.za/publications/643 (accessed 1 December 2009).

8. Department of Health. A National Human Resources for Health Plan for Health to provide skilled human resources for healthcare adequate to take care of all South Africans. 2006. http://www.doh.gov. za/docs/discuss-f.html (accessed 12 October 2008).

9. Tesson G, Curran V, Pong RW, Strasser R. Advances in rural medical education in three countries: Canada, the United States and Australia. Rural Remote Health 2005;5:397 (online).

10. Strasser R, Neusy AJ. Context counts: training health workers in and for rural and remote areas. Bull World Health Organ 2010;88(10):777-782.

11. Igumbor EU, Kwizera EN. The positive impact of rural medical schools on rural intern choices. Rural Remote Health 2005;61:417-421 (online). http://www.rrh.or.au (accessed 27 September 2008).

12. De Vries E, Reid S. Do South African medical students of rural origin return to rural practice? S Afr Med J 2003;93:789-793.

13. Ross AJ. Success of a scholarship scheme for rural students. S Afr Med J 2007;97:1087-1090.

14. Longombe A. Medical schools in rural areas - necessity or aberration? Rural Remote Health 2009;9:1131 Longombe A. Medical schools in rural areas - necessity or aberr
(online). http://www.rrh.org.au (accessed 27 September 2010).

15. Tumbo JM, Couper ID, Hugo JF. Rural origin health sciences students in South African universities. S Afr Med J 2009;99:54-56.

16. Irlam JH, Kiekelame MJ, Vivian LM, 2009. Integrating the primary health care approach into a medical curriculum: a programme logic model. African Journal of Health Professions Education 2009;1(1):8-10.

7. Reid SJ, Cakwe M, on behalf of the Collaboration for Health Equity through Education and Research (CHEER). The contribution of South African curricula to prepare health professionals for working in rural or under-served areas in South Africa: A peer review evaluation. S Afr Med J 2010;101: xxxx (this issue).

18. Norris, T E, Schaad, D C, DeWitt D, Ogur B, Hunt D, members of the Consortium of Longitudinal Integrated Clerkships. Longitudinal integrated clerkships for medical students: An innovation adopted by medical schools in Australia, Canada, South Africa, and the United States. Acad Med 2009;84(7):902-907.

19. Ogur B, Hirsch D, Krupat E, Bor D. The Harvard Medical School-Cambridge Integrated Clerkship: An Ogur B, Hirsch D, Krupat E, Bor D. The Harvard Medical School-Cam
innovative model of clinical education. Acad Med 2007;82(4):397-404

20. Eley D, Baker P. Does recruitment lead to retention? Rural clinical school training experiences and subsequent intern choices. Rural Remote Health 2006;6:511 (online). http://www.rrh.deakin.edu.au (accessed 20 August 2008).

21. Wilkinson D, Birks J, Davies L, Margolis S, Baker P. Preliminary evidence from Queensland that rural clinical schools have a positive impact on rural intern choices. Rural Remote Health 2004;4:340 (online). http://www.rrh.deakin.edu.au (accessed 20 October 2009). 